\title{
Current-Fed Resonant Full-Bridge Boost DC/AC/DC Converter
}

\author{
Soumya.S.Patil $1^{1}$, Nagabhushan.Patil ${ }^{2}$ \\ ${ }^{1,2}$ Department of Electrical and Electronics Engineering, P.D.A.C.E, Gulbarga, Karnataka, India
}

\begin{abstract}
This paper presents a current fed full bridge boost DC/AC/DC converter with transformer isolation. However, Higher frequencies result in the increase of transistor switching losses, and thus, the converter's effectiveness is limited. For this reason, to minimize the converter switching losses this converter with transformer isolation operating without switching power dissipation has been implemented. In the proposed scheme, PIC16F72 controller is used to produce signals. An universal motor of $150 \mathrm{~W}, 30 \mathrm{~V}-90 \mathrm{~V}, 1.6 \mathrm{~A}-5 \mathrm{~A}$ rating and a resistive load(incandescent lamp with different watts) are used as load for testing the developed hardware. Textronics TDS2024B storage oscilloscope is used to store the gate pulses and waveforms.
\end{abstract}

Keywords: MOSFETs, Bridge, Universal motor, DC/DCAC/DC converter, Resonant tank.

\section{Introduction}

A vital factor that determines the size and the cost of a converter is its operation frequency. In order to minimize the size and the cost, the frequency has to be maximized. However, higher frequencies result in the increase of transistor switching losses, and thus, the converter's effectiveness is limited. For this reason, many solutions have been proposed to minimize the converter switching losses. Among these solutions one of the popular method is current fed resonant full-bridge boost converter operating without switching power dissipation .The output voltage is regulated by dc/ac converter control frequency changes with a constant turnoff time MOSFETs. The proposed converter is devoid of parasitic oscillations, as all of the parasitic capacitances and inductances are included in a resonant tank circuit.

These $\mathrm{dc} / \mathrm{ac} / \mathrm{dc}$ converters utilizing an isolation transformer are widely used in different types of applications such as battery chargers and dischargers, uninterruptible power systems, hybrid electric vehicles, medical x-ray, variable dc motor, sewing machine, etc. In high voltage applications, the output filter inductor of the voltage-fed dc-dc converter is bulky and expensive due to the high voltage stress on the inductor. Therefore, a voltage-fed $\mathrm{dc}-\mathrm{dc}$ converter is not preferred in high voltage applications. Current-fed converters are widely used in high voltage applications since an output inductor is not required. Usually, a very high turns-ratio transformer is used to achieve a high output voltage in high voltage applications. In the case of the applications where low input voltages have to be converted to high output voltages, current-fed converters are used, whereas in the case of higher power applications, full-bridge boost converters are usually a good choice.

The main advantage of such systems (in addition to having a voltage gain greater than 1) is that they include a capacitive output filter, which is preferred in higher voltage applications. Moreover, their output rectifier diodes are operated in a discontinuous conduction mode with zero-current switching (ZCS), which is an additional benefit. The developed hardware is tested on an universal motor. A software program is written and is fed to the PIC controller (PIC16F72) for the implementation. The various graphs/waveforms are analyzed and studied on Digital Storage Oscilloscope.

\section{Block Diagram And Its Explanation}

\section{A. System overview}

The block diagram of the proposed current fed resonant full- bridge boost dc/ac/dc converter is shown in fig 1. It has Inverter, Rectifier, Gate drive unit, Control unit Each MOSFET acts as a switch without any switching losses and facilitates the operation of the converter. The inverter is followed by Gate drive unit and a control unit. The primary function of the gate drive circuit is to convert logic level control signals into the appropriate voltage and current for efficient, reliable, switching of the MOSFET module. In this work an optocoupler TLP50 is used to isolate the gate drive circuit and the MOSFET based inverter circuit. The optocoupler consists of an infrared light-emitting Diode and a silicon phototransistor. The input signal is applied to the IRLED and the output is taken from the phototransistor.

The AC voltage is further passed through an step up transformer which step up the input voltage and it also acts as an isolation transformer which isolates output from input variations if any and also the input from load variations. Further the isolation transformer is connected to the rectifier circuit on the other half, where the AC voltage is converted to the DC output voltage. The output rectifier contains some ripples, so the ripple contents can be reduced by using capacitive filter. 
A controller (PIC16F72) is used to implement the core of the control function, which simplifies the hardware setup.

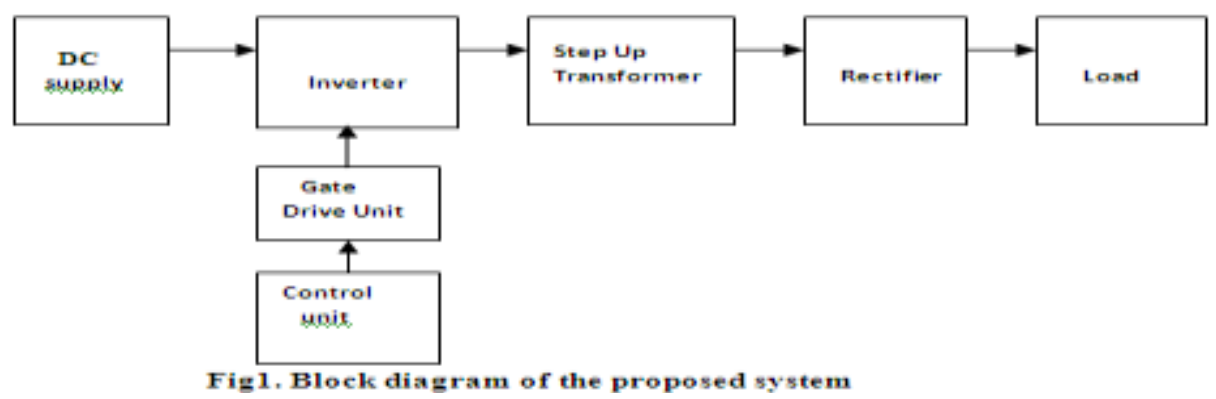

\section{B .Control circuit}

The control circuit of the proposed scheme consists of a Digital signal controller PIC16f72.The microcontroller is operated at $10 \mathrm{MHz}$ crystal frequency. PIC controls power switches in inverter circuit. A control unit $(\mathrm{CU})$ is, in general, a central (or sometimes distributed but clearly distinguishable) part of the machinery that controls its operation, provided that a piece of machinery is complex and organized enough to contain any such unit. The controller decides the instant timing of the gate signal to be given to the MOSFETs in order to avoid overlapping in conduction of incoming and outgoing MOSFETs.

\section{Converter System Description}

The proposed converter circuit is shown in fig. 2. The Circuit consists of two parts one is the inverter and other is the rectifier both separated from each other by an isolation transformer. The inverter converts the low input dc voltage into high power ac output voltage. The output of dc converter with resistive load is discontinuous and contains ripples. The ripple content in the dc output can be reduced by using capacitive filter .

The inductance L1 represents the transformer leakage inductance, the capacitance $\mathrm{C}$ includes the transformer parasitic capacitance, and the capacitances CT include the transistor parasitic capacitances. During the constant break between the control pulses, two transistors and two capacitors alternatively conduct T1T4CT3CT2 or T2T3CT1CT4. Because of the system symmetry, each transistor and each capacitor conducts. The DC input voltage is converted to $\mathrm{AC}$ in order to increase the efficiency of the converter. AC voltage is further passed through an step up transformer which step up the voltage and also acts as an isolation transformer, which isolate output from the input variations if any and also the input from the load variations. The isolation transformer is connected to the rectifier circuit on the other half, where the AC voltage is converted to the DC output voltage.

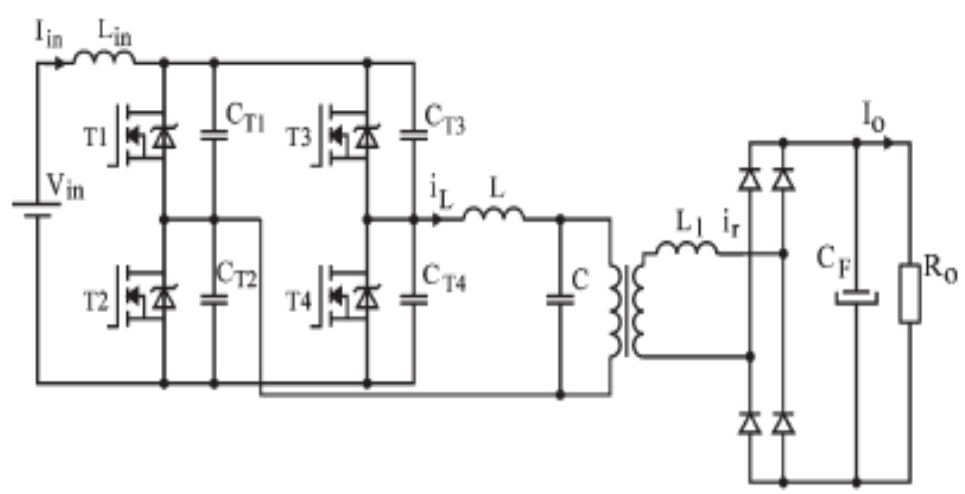

Fig 2 Proposed converter circuit

Each MOSFET acts as a switch without any switching losses and facilitates the operation of the converter. The primary function of the gate drive circuit is to convert logic level control signals into the appropriate voltage and current for efficient, reliable, switching of the MOSFET module. Most gate drive circuits also provide isolation so that the logic signals are not connected to the dangerous high voltage present in the power circuit.

A control unit (CU) is, in general, a central (or sometimes distributed but clearly distinguishable) part of the machinery that controls its operation, provided that a piece of machinery is complex and organized enough to contain any such unit.The control unit of the proposed scheme consists of a controller PIC16F72.DSC controls power switches in the inverter circuit. The controller decides the instant timing of the 
gate signal to be given to the MOSFETs in order to avoid overlapping in conduction of incoming and outgoing MOSFETs.

IV. Experimental Setup And It Results

Table 3.1 Experimental results for Universal motor and Resistive load

\begin{tabular}{|c|c|c|c|c|c|c|c|c|c|c|}
\hline & \multicolumn{2}{|c|}{ Universal Motor } & \multicolumn{8}{|c|}{ Incandescent Iamp } \\
\hline & & & \multicolumn{2}{|c|}{$15 \mathrm{~W}$} & \multicolumn{2}{|c|}{$25 \mathrm{~W}$} & \multicolumn{2}{|c|}{$60 \mathrm{~W}$} & \multicolumn{2}{|c|}{$200 \mathrm{~W}$} \\
\hline & $\begin{array}{l}\text { Boost } \\
\text { Mode }\end{array}$ & $\begin{array}{l}\text { Buck } \\
\text { Mode }\end{array}$ & $\begin{array}{l}\text { Boost } \\
\text { Mode }\end{array}$ & $\begin{array}{l}\text { Buck } \\
\text { Mode }\end{array}$ & $\begin{array}{l}\text { Boost } \\
\text { Mode }\end{array}$ & $\begin{array}{l}\text { Buck } \\
\text { Mode }\end{array}$ & $\begin{array}{l}\text { Boost } \\
\text { Mode }\end{array}$ & $\begin{array}{l}\text { Buck } \\
\text { Mode }\end{array}$ & $\begin{array}{l}\text { Boost } \\
\text { Mode }\end{array}$ & $\begin{array}{l}\text { Buck } \\
\text { Mode }\end{array}$ \\
\hline $\begin{array}{l}D C \\
\text { Irit } \\
\text { Wolige } \\
\text { (Volts) }\end{array}$ & 8.26 & 16.42 & 27.2 & 32.9 & 25.9 & 28.4 & 19.3 & 24.6 & 11.2 & 18.8 \\
\hline $\begin{array}{l}\mathrm{DC} \\
\text { Outut } \\
\text { Volse } \\
\text { (Volts) }\end{array}$ & 38.74 & 21.23 & 178.3 & 117.8 & 157.3 & 99.5 & 116.6 & 78.8 & 62.1 & 42.0 \\
\hline
\end{tabular}

The current fed full bridge boost dc/ac/dc converter developed hardware is tested with load. The proposed control system is implemented by a PIC16F72. C language is used to develop the program. The device is programmed using MPLAB Integrated Development Environment (IDE) tool. It is a free, integrated toolset for the development of embedded applications employing Microchip's PIC and dsPIC controllers. For execution of C-code, MPLAB compiler is used. In this work, I have used 150W,30V-90V,1.6A-5A universal motor and $15 \mathrm{~W}, 25 \mathrm{~W}, 60 \mathrm{~W}, 200 \mathrm{~W}$ incandescent lamp.

The hardware set is developed and tested in power electronics laboratory and the photograph of complete setup is shown in fig 3.3. The test is carried out on universal motor and bulb. DC voltages and DC output voltages for different loads are tabulated.

In the complete experiment the oscilloscope used is Tektronix TDS2024B Digital Storage Oscilloscope (DSO) to store gate pulses and voltage waveforms.

Table 3.1 shows, the output voltages for universal motor and for incandescent lamps of different voltages for both in boost \& buck modes. Fig 3.2.a to 3.2.f. shows the corresponding waveforms taken from the Digital Storage Oscilloscope.

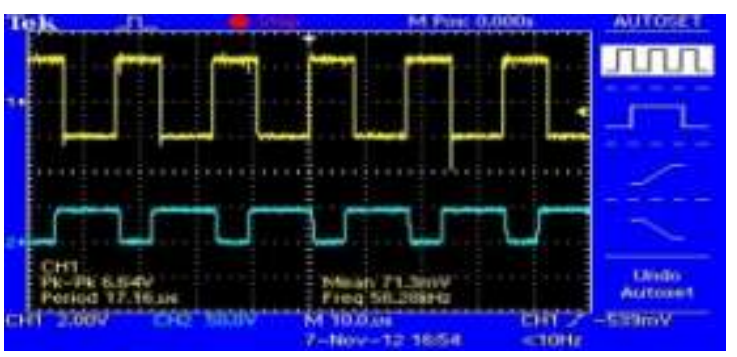

Fig.3.2.a Gate pulse waveform of Boost mode

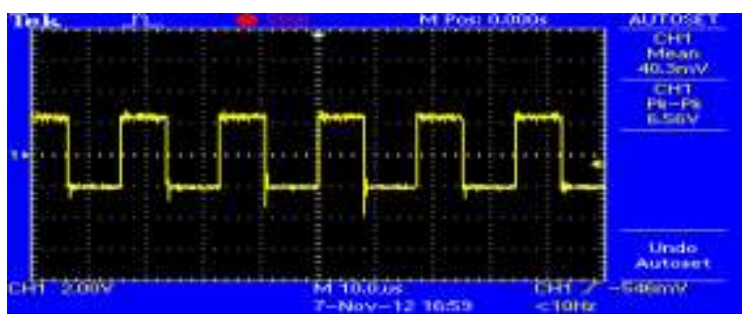

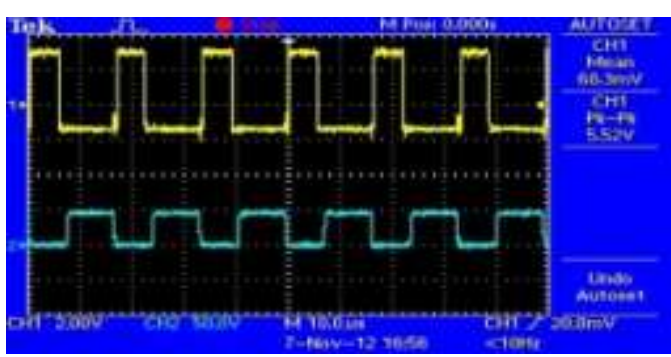

Fig 3.2.b Gate pulse waveform of Buck mode

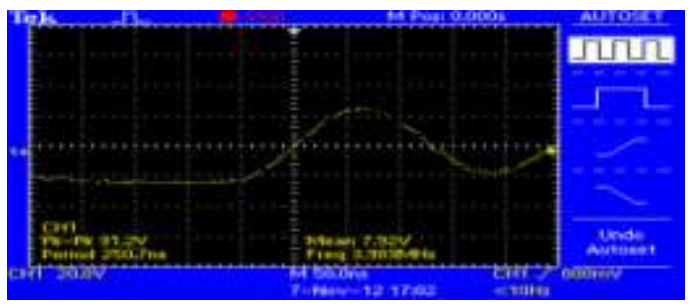

Fig 3.2.c T1: Gate pulse waveform of Boost mode Fig 3.2.d VT1,VT2: Voltages of Transistors T1 \& T2 


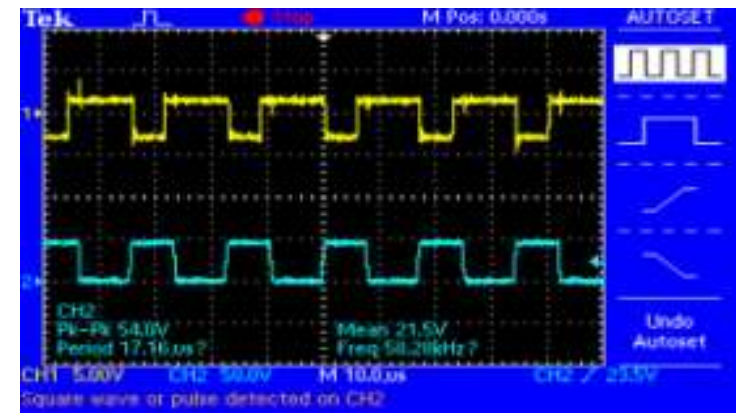

Fig 3.2.e Gate pulse overlap of Boost mode

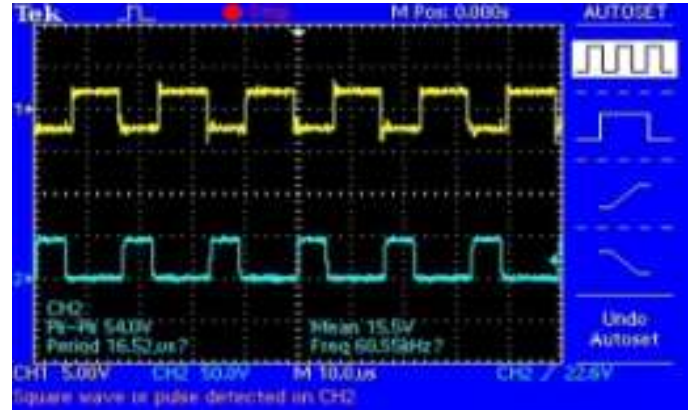

Fig 3.2.f Gate pulse overlap of Buck mode

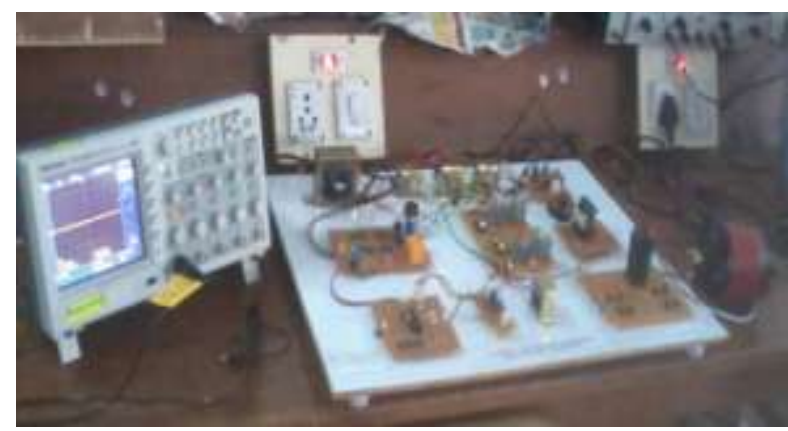

Fig 3.3 Photograph of the complete designed system

\section{Conclusion}

This paper presents a current-fed full-bridge dc/ac/dc converter system with transformer isolation. Due to the fact that all of the parasitic capacitances and inductances are included in the resonant or filter circuits, the system does not generate parasitic oscillations and is devoid of uncontrolled high voltage and current spikes.

The developed hardware setup is tested on a $150 \mathrm{~W}, 30 \mathrm{~V}-90 \mathrm{~V}, 1.6 \mathrm{~A}-5 \mathrm{~A}$ universal motor and a resistive load in power electronics laboratory. From the experimental setup and results chapter it is clear that the developed hardware satisfactory converts DC/AC/DC, \& can be used in Sewing machine, Variable DC motor, Hybrid electric vehicles(HEVs), UPS.

\section{Appendix}

The following defines the nomenclature and system parameters used in this paper :

\section{A. Molar parameters and nomenclature:} 150W, 30V-90V, 1.6A-5A universal motor

\section{B. Inverter parameters:}

Vin: Input voltage 230V CT1, CT2, CT3, CT4 capacitors Q1, Q2, Q3, Q4:MOSFETs

\section{References}

[1] R. Y. Chen, R. L. Lin, T. I. Liang, I. F. Chen, and K. C. Tseng, "Current fed full-bridge boost converter with zero current switching for high voltage applications," in Conf. Rec. IAS Annu. Meeting, 2005, vol. 3, pp. 2000-2006

[2] L. Zhou and X. Ruan, "A zero-current and zero-voltage-switching PWM boost full-bridge converter," in Proc. IEEE PESC Conf., 2003, vol. 2, pp. 957-962.

[3] C. Iannello, S. Luo, and I. Batarseh, "Full bridge ZCS PWM converter for high-voltage high-power applications," IEEE Trans. Aerosp. Electron. Syst., vol. 38, no. 2, pp. 515-526, Apr. 2002

[4] K. Wang, L. Zhu, H. Odendaal, J. Lai, and F. C. Lee, "Design, implementation, and experimental results of bi-directional fullbridge DC/DC converter with unified soft-switching scheme and soft-starting capability," in Proc. IEEE PESC Conf., 2000, pp. $1058-1063$

[5] S.Ajitha, N.Kalaiarasi "Implementation of Full-Bridge Current-Fed Resonant Boost Converter using PIC microcontroller" @2010 International Journal of Computer Applications (0975 - 8887) Volume 1 - No. 7 